\title{
Employees' perceptions of the effectiveness and fairness of performance management in a South African public sector institution
}

\begin{tabular}{|c|c|}
\hline \multicolumn{2}{|c|}{$\begin{array}{l}\text { Authors: } \\
\text { Mpho Makhubela }^{1} \\
\text { Petrus A. Botha }^{1} \text { (D } \\
\text { Sonia Swanepoel }\end{array}$} \\
\hline \multicolumn{2}{|c|}{$\begin{array}{l}\text { Affiliations: } \\
{ }^{1} \text { Faculty of Commerce and } \\
\text { Administration, North-West } \\
\text { University, South Africa }\end{array}$} \\
\hline \multicolumn{2}{|c|}{$\begin{array}{l}\text { Corresponding author: } \\
\text { Petrus Botha, } \\
\text { petrus.botha@nwu.ac.za }\end{array}$} \\
\hline \multicolumn{2}{|c|}{$\begin{array}{l}\text { Dates: } \\
\text { Received: } 01 \text { July } 2015 \\
\text { Accepted: } 26 \text { July } 2016 \\
\text { Published: } 16 \text { Nov. } 2016\end{array}$} \\
\hline \multicolumn{2}{|c|}{$\begin{array}{l}\text { How to cite this article: } \\
\text { Makhubela, M., Botha, P.A., } \\
\text { \& Swanepoel, S. (2016). } \\
\text { Employees' perceptions of } \\
\text { the effectiveness and fairness } \\
\text { of performance management } \\
\text { in a South African public } \\
\text { sector institution. SA Journal } \\
\text { of Human Resource } \\
\text { Management/SA Tydskrif vir } \\
\text { Menslikehulpbronbestuur, } \\
\text { 14(1), a728. http://dx.doi. } \\
\text { org/10.4102/sajhrm. } \\
\text { v14i1.728 }\end{array}$} \\
\hline \multicolumn{2}{|c|}{$\begin{array}{l}\text { Copyright: } \\
\text { (C) 2016. The Authors } \\
\text { Licensee: AOSIS. This } \\
\text { is licensed under the } \\
\text { Creative Commons } \\
\text { Attribution License. }\end{array}$} \\
\hline \multicolumn{2}{|l|}{ Read online: } \\
\hline 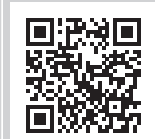 & $\begin{array}{l}\text { Scan this QR } \\
\text { code with your } \\
\text { smart phone or } \\
\text { mobile device } \\
\text { to read online. }\end{array}$ \\
\hline
\end{tabular}

Orientation: The implementation of performance management systems (PMSs) and performance appraisals (PAs) by public managers remains a challenge and necessitates an investigation into employees' perceptions of the effectiveness of the PMS and the fairness of PA.

Research purpose: This study investigated the association between employee involvement, performance-oriented culture, management commitment and the effectiveness of a PMS. Six factors that determine and influence employees' perceptions of PA fairness were also investigated.

Motivation for the study: Employees' experiences of the implementation and practice of PMSs and PAs by public managers may differ from what is intended. The motivation for this study was to quantify employee perceptions of the effectiveness of a PMS and the fairness of PA to establish if there is a discrepancy between what is intended and how they are implemented and practiced.

Research approach, design and method: This cross-sectional study conducted a census on a total population of 140 employees in a public sector institution. A questionnaire comprising three sections was used to collect data: Section A contained biographical questions, Section B comprised questions on the contextual factors that measure the perceived effectiveness of the PMS while Section C comprised questions related to the perceived fairness of PA.

Main findings: The results show that employees perceive their PMS to be ineffective and their PAs to be unfair. The mean perception scores for PA fairness for the Assets and Facilities Department were significantly lower than those of the Human Resources Department. This is indicative of some deficiencies in the appraisal process in the Assets and Facilities Department. Respondents occupying general positions returned significantly lower mean scores for PA fairness compared to those in managerial and professional positions, which indicates serious shortcomings in their appraisal process.

Practical/managerial implications: The findings reveal that employees were not involved in the development of the PMS. Also, the results indicated a lack of employee participation in the PA process, that PAs were not conducted for development purposes, performance feedback sessions were not undertaken on a regular basis and employees were not involved in goal setting. A training programme should address these organisational and managerial deficiencies.

Contribution: This research study contributes to the body of knowledge by quantifying the perceptions of employees regarding the organisational factors that influence the effectiveness of the PMS and the six factors, namely appraisers' knowledge, employee participation, clear goal establishment, employee development, goal establishment, appraisal follow-up and goal discussion that influence PA fairness.

\section{Introduction}

\section{Key focus}

This study focuses on employees' perceptions of the effectiveness and fairness of performance management. Public managers are perceived as lacking the knowledge and skills to implement performance management effectively. Comprehensive research is needed to fully understand the effectiveness of performance management systems (PMSs) in organisations, especially from employee perspectives (Sharma, Sharma \& Agarwal, 2016). This article reports on a study conducted among employees in a South African public sector institution to measure the impact of employee involvement, performance-oriented culture and management commitment to the 
effectiveness of the PMS. Also, employees' perceptions of the fairness of performance appraisals (PAs) were measured on six factors, namely appraiser's knowledge, employee participation, employee development, goal establishment, appraisal follow-up and goal discussion.

There are various factors that can be used to measure employees' perceptions of Performance Management System Effectiveness (PMSE), but there seems to be a lack of clarity among researchers on how to define the construct effectiveness in the context of performance management and what indicators to use to measure employees' perceptions. In their study, Sharma et al. (2016, p. 225) used two constructs namely, accuracy and fairness to measure PMSE. Their most significant contributions are the theoretical development of the construct of effectiveness and the validation of an accuracy and fairness scale. Only four factors, namely personal development, employees' personal performance, informed about the performance management and development system and management support, were used to measure PMSE in a study conducted by Ramulumisi, Schultz and Jordaan (2015). However, one of the factors, namely informed about performance management and development system, was unreliable and excluded from the analysis. Dewettinck and Van Dijk (2013) assessed the PMSE in a public sector institution in the Netherlands using Dewettinck's (2008) Motivational Effect of Performance Review Scale. The limitation of their study is that the scale focuses only on performance reviews, which is only one phase in PMS. Haines and St-Onge (2012) studied PMSE using a scale that measures positive performance management outcomes. Research in PMSE is characterised by measurement inconsistencies and lack of theoretical groundings for the construct of effectiveness in the PMS context. Employees' perceptions of PMSE has not been adequately conceptualised and operationalised in previous research. The different scales developed to measure PMSE failed to include all the different phases of performance management. The main problems are that public service employees' have negative perceptions of the effectiveness and fairness of the PMS because of deficiencies in organisational factors and the manner in which line managers implement and practice performance management.

The objectives of this study are firstly to provide an empirical analysis of the association between three organisational factors, namely employee involvement, performanceoriented culture and management commitment, and the effectiveness of the PMS. Secondly, the study investigates the factors that determine employees' perceptions of PA fairness. Measuring perceptions of the effectiveness of the PMS and PA fairness allow for the exploration of employee experiences of the PMS practices that are implemented by line managers in a public sector institution.

This study contributes to the body of knowledge in the effectiveness of the PMS by providing a theoretical framework of the factors that influence the effectiveness of performance management and quantifying employees' perceptions regarding the organisation and PA factors that influence the effectiveness and fairness of the PMS. The knowledge of the employees' perceptions of the PMS in the public sector institution will assist public managers to implement such a system more effectively.

\section{The research questions that were investigated include the following:}

- What are employees' perceptions of the effectiveness of the PMS?

- What are employees' perceptions of the fairness of PA?

- Is there a difference in the mean perception scores for the effectiveness of the PMS and the fairness of PA between male and female employees and employees of different age groups, departments and positions?

- Is there a correlation between the mean perception scores of the effectiveness of the PMS and the fairness of PA?

In the following sections of this article, the researchers outline the literature review and research design followed by a presentation of the results. Finally, they discuss the results, highlight the practical implications, outline limitations and make recommendations for areas of future research.

\section{Literature review}

Deb (2008, p. 25) defines a PMS as a tool that comprises interrelated parts, which together form an independent whole where the whole is greater than the sum of its parts and which strives to maintain equilibrium. Armstrong (2009, p. 618) defines performance management as a systematic process for improving organisational performance by developing the performance of individuals and teams and getting better results by understanding and managing performance within an agreed upon framework of planned goals, standards and competency requirements.

Swanepoel, Erasmus and Schenk (2009, p. 368) define PA as a separate but central subset of overall performance management. It is simply the process of formally evaluating work performance, making decisions on the effective utilisation of rewarding and motivating staff, rectifying substandard performance and providing feedback to individual employees. PAs are a core element of human resource management because the results of appraisals are used as the foundation for many human resource decisions. PAs are done for various purposes, such as career development and accountability and are linked to recognition and compensation. They are also used in disciplinary procedures and decisions regarding salary increment and promotion (Ahmad \& Azman Ali, 2004, p. 49).

In Public Management, performance measurement and management systems are key elements in improving government performance and accountability. The public sector is increasingly devoting more time to performance management, measurement and evaluation. Performance measurement is not synonymous with PMS. Performance management is viewed more broadly as a management tool 
that aims to improve the performance of an organisation while performance measurement focuses more narrowly on the metrics used to determine how an organisation is performing (Goh, 2012, p. 32). According to McAdam, Hazlett and Casey (2005, p. 258), the objectives of performance management are rationalism in terms of size, cost and functions; greater transparency in the operation of public institutions; the upgrading of the skills base in the public sector and modernisation of its functional principles, procedures and systems; and the development of a realistic remuneration policy based on performance. Verbeeten (2008, p. 430) states that performance management can serve four purposes for public managers. Firstly, it helps define clear missions, objectives and targets, which assist individuals in understanding what is expected of them. Secondly, by measuring performance regarding objectives, politicians and public managers can account to the public on how taxpayers' money is spent. Thirdly, public sector organisations can use performance measurement to improve performance, and lastly, the PMS can serve as a basis for the compensation of government employees. Sole (2009, p. 4) developed a management model for public organisations to better understand performance measurement and PMSs. The model distinguishes between three organisational levels, namely the strategic level, the operational level and the team or individual level. The focus of this study is on performance management at an individual level. The process of managing individual performance is similar to managing performance at the organisational level, and the process starts at the top of the organisation with management developing a performance management policy. Managers control performance by influencing outputs and the feedback provided by outputs.

The ultimate goal of a performance management process is to align individual performance with organisational performance and should indicate to employees the organisation's goals, priorities and expectations and how well they contribute to these (Selden \& Sowa, 2011, p. 252). A typical performance management process consists of five phases, namely performance planning, ongoing feedback, employee input, performance evaluation and performance review (Pulakos, 2004, p. 4). However, Gruman and Saks (2011, pp. 127-128) propose a new model that begins with performance agreement; engagement facilitation; performance and engagement appraisal; and feedback, employee engagement and improved performance. In the public sector institution, where this study was conducted, performance management is known as the Integrated Performance Management System (IPMS). Their regulatory framework is guided by the IPMS Directive (2011), which serves to establish and sustain a standardised system of performance management. According to the Human Resources Directive (2011), individual performance management should include the following:

- performance planning - performance contracting of members

- performance agreement-formal interview to be conducted with every member by line manager in his or her span of control at the beginning of the performance cycle
- performance agreement interview - interview shall be conducted before the end of April each year or within 1 month after appointment

- PA - based on performance agreement and shall serve to provide a member with feedback from the supervisor about his or her performance

- performance cycle - shall be aligned to the financial year and it shall extend from 01 April to 31 March of the following calendar year

- performance categories - unacceptable $(20 \%-29 \%)$, needs improvement $(30 \%-49 \%)$, satisfactory $(50 \%-69 \%)$, above average $(70 \%-84 \%)$ and outstanding $(85 \%-100 \%)$

- management of unsatisfactory performance

- integrated performance management (IPM) rewards

- management of performance in exceptional cases

- performance enhancement - personal development plan shall be compiled.

The development of the policy and practice guidelines for an individual PMS is a human resource management function. However, line managers enact performance management, including PAs. Employees' satisfaction with the PMS and PAs are a good indicator of the effectiveness and viability (Culbertson, Henning \& Payne, 2013, p. 189). However, employees' experiences of the PMS may differ from what is intended. Employees' acceptance of and satisfaction with the PMS and PA are vital for their optimal effectiveness. These perceptions are formed by the manner in which these practices are implemented by line managers.

\section{Effectiveness factors for performance management systems and appraisal fairness}

Researchers have investigated the factors that influence the effectiveness of PMSs and the fairness of PAs. Haines and St-Onge (2012) studied the mutual influence of practice and context on performance management effectiveness in both public and private sector organisations in Canada. Their results indicate a positive relationship between performance management practices, such as performance training and employee recognition, and performance management effectiveness (Haines \& St-Onge, 2012, p. 1165). Furthermore, their results identify three contextual variables that are positively associated with performance management effectiveness, namely organisational culture, employee relations climate and strategic integration of human resource management (Haines \& St-Onge, 2012, pp. 1165-1168). The key features of a successful PMS are the alignment of the PMS with the existing systems and strategies of the organisation; leadership commitment; a high-performance culture; stakeholder involvement; and continuous monitoring, feedback and dissemination of and learning from results (Fryer, Antony \& Ogden, 2009, p. 480). Sole (2009, pp. 7-8) distinguishes between external and internal factors that influence PMS. He identifies the internal factors to be leadership and internal management commitment, investment of internal resources, performance-oriented culture, employee engagement and maturity of the PMS. The external factors he identifies are citizen support and support 
of elected officials, labour union involvement and compliance with legal requirements. Apart from the abovementioned internal factors, Tung, Baird and Schoch (2011, p. 1292) identify the link between performance and rewards as an additional internal critical success factor.

Brown, Hyatt and Benson (2010) investigated the relationship between employees' experiences of the quality of PAs, job satisfaction, organisational commitment and intention to quit in a large public institution in Australia. Their results show that low-quality experiences of PAs are associated with lower levels of job satisfaction. They also found a significant negative relationship between low-quality experiences of PA and organisational commitment. Low-quality experiences of PA are significantly positively related to intention to quit (Brown et al., 2010, pp. 389-390). Therefore, the impact of low-quality experiences of PA results in lower job satisfaction and organisational commitment and higher intentions to quit. The research findings of Tuytens and Devos (2012) indicate that employee participation, charismatic leadership of evaluators, positive perceptions of procedural justice and positive experiences of feedback all have a positive effect on the perceived fairness of PAs. Also, the results of a study conducted by Ahmed, Ramzan, Mohammad and Islam (2011, p. 18) show a positive and significant relationship between the perceived fairness of PA and organisational commitment.

This study focuses on three internal organisational factors that influence the effectiveness of the PMS, namely employee involvement, performance-oriented culture and management commitment. The questionnaire that was developed and validated by Mansor, Chakraborty, Yin and Mahitapoglu (2012) was used for this study.

\section{Employee involvement}

Martin and Davis (2001) argue that the level of employees' involvement and motivation may have a great impact on the success of a PMS and encourages employees to be accountable and to contribute to solutions. Employees need to be actively involved in the designing of a PMS. Most organisations design the workplace approach to ensure that employees are committed to their goals and values and are, on the one hand, highly motivated to ensure the success of their organisations and, on the other hand, to ensure that they enhance their own sense of well-being.

\section{Performance-oriented culture}

Organisational culture is another critical factor for improving the effectiveness of performance management. Sole (2009) states that:

culture can be determined by people's total beliefs, ideologies, behaviours and values that are prevalent in the organisations, and which can influence organisation power relationships and their response to change. (p. 8)

The main factors characterising a performance-oriented culture are a focus on the end result for users and citizens employees' empowerment in taking responsibility without fear of blame and a positive approach to performance management by considering it to be a tool for improvement and not merely a form-filling exercise.

\section{Management commitment}

Sanger (2008, p. 77) argues that an effective PMS require a committed leader who has considerable skills, who is willing to provide significant managerial investment and rewards and willing to design and deploy effective performance measurement and management systems. Poister (2008) also highlights that the involvement of senior executives and managers is a necessary part of successful performance measurement and management systems. In particular, internal management commitment brings a formality to the performance management reviews that could influence employees' commitment to achieving targets and improving performance.

\section{Performance appraisal fairness}

The literature suggests that employees will only be satisfied with a PA process if criteria of 'fairness' are expressed regarding organisational justice. Furthermore, training in the PA process that causes discrepancies between expected and actual performance assessments contributes to dissatisfaction with the system. According to Messer and White (2006), employees' perceptions of fairness can affect their behaviour, especially regarding their contribution to organisational goals. In this case, perceived unfairness and ineffectiveness of the PMS can result in employees not being productive and showing some negativity towards the system. Employees' perceptions of PA are critical in determining the system's effectiveness. Some authors have applied organisational justice theory to PA. Perceptions of the fairness of PA are determined by the feelings expressed by both management and employees about the existence of a formal appraisal system, the knowledge of the supervisor about the performance of the subordinate, the existence of action plans to improve performance weaknesses and the frequency of evaluations (Ahmed et al., 2011, p. 15).

Narcisse and Harcourt (2008, p. 1152) and Vasset, Marnburg and Furunes (2010, p. 31) postulate that employees' perceptions of the fairness of the appraisal system are influenced by distributive, procedural and interactional justice. Distributive justice focuses on the fairness of the evaluations received about the work performed (Greenberg, 1986, p. 340). Employees expect outcomes to be commensurate with inputs in the form of experience, ability and effort. Procedural justice refers to the fairness of the evaluation procedures used to determine the ratings (Greenberg, 1986, p. 340). Interactional justice refers to people's concerns regarding the quality of the interpersonal treatment and communication they receive. It is important to mention that interactional justice focuses on how formal agents of the organisation treat those who are subject to their authority, decisions and actions. According to Rowland and 
Hall (2013, p. 196), interactional justice is sometimes divided into interpersonal justice (how people are treated) and informational justice (how people are informed of the reasons why outcomes are distributed and why particular procedures are used). The manner in which a line manager performs the appraisal process (procedural justice) and the personal communication between the line manager and employee during this process (interactional justice) influence how fair the employee believes the appraisal process to be (Farndale \& Kelliher, 2013, p. 880). Palaiologos, Papazekos and Panayotopoulou (2011, pp. 832-834) postulate that the administrative purpose of PA is related to distributive justice and procedural justice. If organisations use the data recorded during a PA to make decisions regarding payroll, increases in fringe benefits, promotion and employment termination, they create a positive impression about the fairness of both the procedure and its outcomes. Their results also indicate that the development purpose of PA is related to interactional justice and shows a positive relationship between employees' personal development and good interpersonal relationships. Furthermore, their results show that employees' perceptions of the various criteria (goals they need to attain, their behaviour in the execution of their duties, their competencies, their personal characteristics and level of control over their work) used for PA are positively related to procedural justice. Employees' satisfaction with ratings was positively related to distributive justice and a positive relationship between interactional justice and satisfaction with the latter. They have also found a significant relationship between distributive justice and satisfaction with feedback.

Brown and Benson (2003, p. 76) conducted a study among employees in a large public sector research institution in Australia to investigate the relationship between procedural justice, distributive justice and performance ratings. Their results indicate that both distributive and procedural justice are negatively and statistically related to emotional exhaustion while higher ratings by supervisors are associated with higher levels of emotional exhaustion. The results indicate that PA systems that are perceived to have fair processes and that generate fair outcomes are associated with lower emotional exhaustion. Kavanagh, Benson and Brown (2007, p. 133) investigated the role of employees' participation, attitudes towards the supervisors and knowledge of the PA system in promoting employees' perceptions of PA fairness. Their results show that higher levels of two-way communication and involvement in the setting of objectives have a significant and positive effect on PA fairness. The perceived neutrality in the conduct of the PA by the supervisor has a significantly positive effect on PA fairness. Lastly, knowledge of the appraisal system was measured using three variables, namely the levels of clarity, understanding and acceptance of objectives of the PA system. Each of these variables has a positive and significant influence on perceived fairness. The study by Dewettinck and Van Dijk (2013, p. 816) revealed the following: more frequent formal appraisal reviews have a positive effect on PM effectiveness; the frequency of informal performance reviews is positively related to PMS effectiveness; performance reviews that focus more on employee development are associated with higher levels of PMS effectiveness than performance reviews that focus more on performance evaluations; and positive relationships exist between high levels of participation and the PMS effectiveness.

The factors that are considered to influence the fairness of the appraisal system are appraisers' knowledge, employee participation, clear goal establishment, employee development, goal establishment, appraisal follow-up and goal discussion. These factors are based on the questionnaire developed and validated by Evans and McShane (1988).

\section{Appraiser's knowledge}

Saeed and Shahbaz (2011, p. 58) identify an important additional factor that influences the perceived fairness of the appraisal system. This factor relates to employees' knowledge of how they are doing, their dread at receiving appraisals and managers who may despise assessing them. According to them, this factor will result in the system failing because it forces ranking and pits people against each other, which ultimately results in damage to teamwork and the achievement of the broader group goals. Also, the system mixes monetary and other rewards with development improvement goals, therefore creating conflicting objectives (do I want to get the highest rating or acknowledge skills gaps that I could improve on in the future). Managers need ample training to set realistic goals and provide meaningful feedback and coaching (Smither \& London, 2009, p. 73). Armstrong (2009, p. 631) found that many employees feel that their managers are not skilled enough to discuss their performance and coach them on how to improve their performance and that the attitudes of managers and employees result in poor performance management. Furthermore, Armstrong (2009, p. 631) indicates that it is sometimes difficult for managers to give their employees a bad rating during the appraisal interview because they are unable to justify their criticisms, which may be an experience that managers do not want to go through. Therefore, it is much easier for managers to simply give an average rating on the scale and hope the employee will improve somehow. However, this strategy can lead to rating drift, where managers are happy to raise the rating of their employees but never reduce the ratings, even when justified. Nel et al. (2011, p. 418) support these findings and mention that performance evaluations are fraught and dangerous because employees become optimistic knowing that increases, career progress and peace of mind may well rest on how they are rated. Unclear standards will always create problems in performance management. Managers should receive training in supervision skills, coaching and counselling, conflict resolution, setting performance standards, linking the system to pay and how to provide feedback to subordinates (Appelbaum, Roy \& Gilliland, 2011, p. 573). 


\section{Employee participation}

Narcisse and Harcourt (2008, p. 1160) found that 'employee participation in setting standards is highly uncommon', as many participants in their study complained that standards were lacking and wanted more involvement in standard setting. Employee participation in such discussions means that each employee knows what the standards are, and performance limitations are taken into consideration when setting realistic targets. Pettijohn, Pettijohn, Taylor and Keillor (2001) postulate that PAs can be used to improve employees' levels of job satisfaction, organisational commitment and work motivation, but only if there are perceptions of fairness and participation. According to Messer and White (2006), employees' perceptions of fairness can affect their behaviour in contributing to organisational goals. In this regard, perceived unfairness and ineffectiveness of the PA process can result in employees not being productive and showing some negativity towards the system. Vasset, Marnburg and Furunes (2011) further explain that many organisations are unable to examine the importance of participation in PA and that there are mixed effects because they fail to recognise the complexity of the phenomenon. Researchers indicate that managers must support their subordinates in self-determination and must understand and acknowledge their needs, feelings and attitudes.

\section{Employee development}

Boachie-Mensah and Seidu (2012, p. 73) state that employees are likely to embrace and contribute meaningfully to a given PA system if they perceive it to be an opportunity for promotion or an avenue for personal development. They may also perceive it to be a chance to be visible and demonstrate skills and abilities, as well as an opportunity to network with others in the organisation. The authors' further outline that PAs will be effective if the process is clearly explained and agreed upon by the people involved. Also, a successful appraisal is based on employee motivation, attitude and behaviour development; communicating and aligning individual and organisational aims; and fostering positive relationships between management and employees.

\section{Clear goal establishment and discussion}

During the goal-setting stage, individuals should be informed of and understand the organisational goals and objectives and should determine their own goals within this context (Gruman \& Saks, 2011, p. 128). The organisational goals should be cascaded down to departmental and individual goals. Gruman and Saks (2011, p. 128) argue that goals be extremely important for initiating the employee engagement process, because, they say, goals always stimulate energy and allow employees to focus and develop feelings of being engaged. The findings of a study conducted in public sector institutions in the Netherlands indicate that the definition of clear and measurable goals is positively associated with both quantity performance (efficiency, production targets) as well as quality performance (accuracy, innovation, employee morale) (Verbeeten, 2008, p. 442).
Locke and Latham (2002) state that goals drive performance because they affect employees' direction, effort and persistence. This means that where there is direction, employees will focus their attention on the action that will bring about goal establishment. Similarly, goals will lead employees to adjust and persist in their efforts and stimulate the development of task strategies to attain the goals. Goals should be specific and not difficult. In other words, a specific and challenging goal lead to higher performance than general goals such as 'do your best'. It may be presumed that participating in goal setting enhances its effectiveness, and goal setting is likely to be more effective when people participate in setting goals than when goals are assigned to them (Seijts \& Latham, 2005). Managers and employees must set performance standards and targets that are SMART (specific, measurable, achievable, realistic and time-limited) (Stredwick, 2005, p. 297).

\section{Appraisal follow-up}

Aguinis (2009, p. 226) explains that follow-up or feedback to PA is a very challenging stage during which many supervisors who manage performance often feel uncomfortable, especially about performance reviews, because managing performance requires that they judge and coach at the same time. The results of a study conducted by Culbertson et al. (2013, p. 191) reveal that positive feedback is positively related to PA satisfaction while negative feedback is negatively related to PA satisfaction. Furthermore, Aguinis (2009, p. 226) mentions that performance reviews are very important as they allow employees to improve their performance through the identification of performance problems and their solutions. When standards and targets are set, there will be a differentiation between good and bad performance. However, if PA gaps are found in the employee's goals and actual performance, this should be discussed and feedback must be given to the employee. The manager must be able to find the root causes of performance gaps. It is important to maintain this pattern of give-and-take with the employee because it will lead to the identification of the source of the problem. Identifying the source of the performance gaps will, in most cases, create an atmosphere of objectivity in which both parties can contribute in positive ways. Nel et al. (2011, p. 301) suggest that when problems are being identified in assessing performance standards, specific goals and timetables should be established for improvement. They are of the view that employees should be given the opportunity to respond to negative appraisals and to give their version of the facts. This may minimise complaints and will help employees to participate in the PA process. Employees must also be given the opportunity to appeal their ratings to ensure a fair system and be provided with a real opportunity to respond to their ratings.

\section{Method}

\section{Research approach}

Most research on the effectiveness of PMSs followed a quantitative approach. Therefore, a quantitative research 
approach was used for this study. Quantitative research is used to answer questions about the relationships among measured variables with the purpose of explaining, predicting and controlling phenomena (Leedy \& Omrod, 2005 , p. 94). Quantitative research is concerned with the responses of participants. Therefore, an explanatory design was used to find answers to the research questions. A crosssectional survey design was used to gather primary data from the participants to achieve the objectives of the study. According to Babbie (2004, p. 89), a cross-sectional survey is defined as a study based on observations representing a single point in time. This study was conducted using a quantitative explanatory paradigm enabling the researchers to generate statistical analysis to investigate the objectives of this study.

Various other studies have also opted to follow a quantitative survey design approach to measure employees' perceptions of the effectiveness and fairness of performance management (Dewettinck \& Van Dijk, 2013; Hanes \& St-Onge, 2012; Ramulumisi et al., 2015; Sharma et al., 2016).

\section{Research design}

\section{Research participants}

The population in this study comprised 140 permanent and fixed-term contract employees in the Department of Training at a South African public institution in Mahikeng, North-West Province. A census was done on the total population. In total, 140 questionnaires were distributed and 81 responses were received from the population of 140 . This is a response rate of $58 \%$. The age group that provided the largest response was between the 35- and 44-year group $(48.1 \%), 59.3 \%$ of the responses were women, $56.8 \%$ were employed between 5 and 9 years, $42.5 \%$ were from the Assets and Facilities Department and 54.3\% occupied a general position.

\section{Measuring instruments}

Two constructs were consequently measured, namely the effectiveness of the PMS and fairness of the PA. The questionnaire was divided into three sections, namely: Section A: Biographical Information, Section B: Performance Management System Effectiveness and Section C: Performance Appraisal Fairness.

\section{Performance Management System Effectiveness Questionnaire}

The PMSEQ (Performance Management System Effectiveness Questionnaire) was compiled from three organisational factors that influence the effectiveness of PMS. The questionnaire focused on three organisational factors and consisted of 12 items that measure the effectiveness of the PMS, namely Employee Involvement, PerformanceOriented Culture and Management Commitment. The instrument was validated in a study by Mansor et al. (2012, p. 588). The Cronbach's alpha values in their study were as follows: Factor 1 (Employee Involvement), 0.84; Factor 2
(Performance-Oriented Culture), 0.81; and Factor 3 (Management Commitment), 0.81. Cronbach's alpha values $>0.70$ showed that all the items were statistically reliable and that the entire test was internally consistent. The PMSEQ reported the following Cronbach's alpha coefficients for the subscales of the instrument used in this study, namely Employee Involvement (0.732), Performance-Oriented Culture (0.204) and Management Commitment (0.704) (see Table 1).

The Performance-Oriented Culture construct was found to be unreliable and was excluded from the data analysis. This Performance Management System Effectiveness Scale reported a Cronbach's alpha of 0.616 for the instrument's reliability. The Performance Management System Effectiveness Questionnaire contains the following components:

- Employee Involvement (five items)

- Performance-Oriented Culture (four items)

- Management Commitment (three items).

A 5-point Likert scale was utilised to measure participants' perceptions of the PMSE ranging from 1 (strongly disagree) to 5 (strongly agree).

\section{Performance Appraisal Fairness Questionnaire}

This instrument aims to measure the employee's perceptions of the fairness of PA. The instrument was validated by a study done by Evans and McShane (1988). In their study, the Cronbach's alpha values for the six variables ranged from 0.64 to 0.88 , thus confirming that the items used for the different factors were reliable and valid. The Performance Appraisal Fairness Questionnaire (PAFQ) used in this study reported the following Cronbach's alphas for the subscales: Appraiser Knowledge (0.746), Employee Participation (0.857), Employee Development (0.637), Goal Establishment (0.828), Appraisal Follow-up (0.886) and Goal Discussion (0.617). This Performance Appraisal Fairness Scale reported a Cronbach's alpha of 0.917 for the instrument's reliability (see Table 2).

TABLE 1: Cronbach's alpha for three subscales of the effectiveness of the performance management system scale.

\begin{tabular}{lcc}
\hline Subscales & Cronbach's alpha & Number of items \\
\hline Employee involvement & 0.732 & 5 \\
Performance-oriented culture & 0.204 & 4 \\
Management commitment & 0.704 & 3 \\
\hline Total scale & $\mathbf{0 . 6 1 6}$ & $\mathbf{1 2}$
\end{tabular}

TABLE 2: Cronbach's alpha for the six subscales of the performance appraisal fairness scale.

\begin{tabular}{lcc}
\hline Subscales & Cronbach's alpha & Number of items \\
\hline Appraiser knowledge & 0.746 & 5 \\
Employee participation & 0.857 & 5 \\
Employee development & 0.637 & 4 \\
Goal establishment & 0.828 & 3 \\
Appraisal follow-up & 0.886 & 2 \\
Goal discussion & 0.617 & 2 \\
\hline Total scale & $\mathbf{0 . 9 1 7}$ & $\mathbf{2 1}$ \\
\hline
\end{tabular}


The PAFQ contains the following components:

- Appraiser's Knowledge (five items)

- Employee Participation (five items)

- Employee Development (four items)

- Goal Establishment (three items)

- Appraisal Follow-up (two items)

- Goal discussion (two items).

Thus, the PAFQ consists of 21 close-ended questions. The employees' perceptions of the appraisal fairness were indicated on a 5-point Likert scale ranging from 1 (strongly disagree) to 5 (strongly agree). To prevent response bias, the wording of four items have been negatively worded and was reversed scored.

\section{Research procedure}

The primary researcher was granted permission by the Director-General to distribute questionnaires to all employees of the public sector institution. The questionnaires were distributed via email. The completed questionnaires were returned to the researcher by hand and via the intranet. The questionnaires have been circulated to participants with an attached letter of consent explaining the purpose of the study. The letter of consent included a description of the research, protection of confidentiality and voluntary participation, the importance of participation, potential benefits and contact information for the researcher. The general instructions on how to complete the questionnaire were also included. The collection of data took place over a period of 3 weeks. This allowed participants with enough time to complete questionnaires at their convenience.

\section{Statistical analysis}

Data were analysed using the Statistical Package for Social Sciences (SPSS - version 22). Descriptive statistics were analysed by determining the minimum and maximum scores, means and standard deviations (SDs). Cronbach's alpha reliabilities were analysed to determine the internal consistency and reliability of the questionnaires.

An independent $t$-test was conducted to compare the mean perception scores on the effectiveness of the PMS and PA fairness between the male and female employees. Analysis of variance (ANOVA) was conducted to compare the mean perception scores of employees' of the effectiveness of the PMS and PA fairness between age groups, departments and positions occupied. The Pearson product-moment correlation coefficient was used to measure the strength of the relationship between perceptions of employees on the effectiveness of the PMS and PA fairness.

\section{Results}

Four control variables were included in the analysis: gender was included as a dichotomous variable; age group was measured on a 5-point scale ranging from less than 25-55 years and over; department was measured on a 5-point scale based on the actual number of departments and position was measured on a 3-point scale based on the actual job titles.

Descriptive statistics (the overall mean and SD) for each of the two organisational factors are depicted in Table 3.

The mean score for employee involvement (1.72) was lower than the mid-point of the range, suggesting that employees were not involved with or engaged in the PMS. The mean score for management commitment (2.88) was slightly higher than the mid-point of the range, indicating that on average employees perceived management commitment to be moderately effective. The mean score for the effectiveness of the PMS (2.33) was slightly lower than the mid-point of the range indicating that on average the employees assessed their PMS to be ineffective.

The following mean scores were returned on the subscales for the six factors related to PA fairness: appraiser's knowledge, 2.50; employee participation, 2.10; employee development, 2.35; goal establishment, 2.09; appraisal followup, 1.80; and goal discussion, 2.32 (see Table 4). The overall mean score for the scale was 2.19. Except for the appraiser's knowledge subscale all the subscales and scale obtained mean scores that were lower than the mid-point of the range indicated that, on average, the employees perceived their PA to be unfair.

An independent-samples $t$-test was conducted to compare the mean perception scores for the effectiveness of the PMS with the fairness of the appraisal process between men and women. There were no significant differences in the perception scores for either the PMS effectiveness or PA fairness between men and women. One-way betweengroups ANOVAs were conducted to explore the impact of different age groups, departments and positions on the perceptions of the effectiveness of the PMS and PA fairness. There were no statistically significant differences in the mean scores of the four age groups, departments and positions regarding the perception levels of the PMS. However, there

TABLE 3: Means and standard deviations for the two organisational factors and average mean for the performance management system scale.

\begin{tabular}{lccccc}
\hline Subscales and scale & $\boldsymbol{N}$ & Minimum & Maximum & Mean & SD \\
\hline Employee involvement & 81 & 1.00 & 4.00 & 1.77 & 0.66 \\
Management commitment & 81 & 1.00 & 4.00 & 2.88 & 0.80 \\
Average mean of PMS scale & 81 & 1.00 & 4.00 & 2.33 & 0.52 \\
\hline
\end{tabular}

PMS, performance management system; SD, standard deviation.

TABLE 4: Means and standard deviations for the six factors and mean score for the performance appraisal scale.

\begin{tabular}{lccccc}
\hline Subscales and scale & $\boldsymbol{N}$ & Minimum & Maximum & Mean & SD \\
\hline Appraiser's knowledge & 81 & 1.00 & 4.60 & 2.50 & 0.78 \\
Employee participation & 81 & 1.00 & 4.00 & 2.10 & 0.88 \\
Employee development & 81 & 1.00 & 3.75 & 2.35 & 0.67 \\
Goal establishment & 81 & 1.00 & 4.33 & 2.09 & 0.89 \\
Appraisal follow-up & 81 & 1.00 & 4.50 & 1.80 & 0.86 \\
Goal discussion & 81 & 1.00 & 4.00 & 2.32 & 0.94 \\
$\begin{array}{l}\text { Average mean of } \\
\text { performance appraisal scale }\end{array}$ & 81 & 1.10 & 3.72 & 2.19 & 0.64 \\
\hline
\end{tabular}

SD, standard deviation. 
was a statistically significant difference at the $p<0.05$ level of the PA fairness scores between the five departments $(F[4,76]=4.7, p=0.002)$. Post hoc comparisons using the Scheffe test indicated that the mean score for the Human Resources Department $(M=2.75, \mathrm{SD}=0.64)$ was significantly different from the Assets and Facilities Department $(M=1.91$, $\mathrm{SD}=0.68$ ). There was also a statistically significant difference at the $p<0.05$ level of the PA fairness scores between the three positions $(F[2,78]=9.15, p=0.000)$, where the mean score for the manager position $(M=2.62, \mathrm{SD}=0.43)$ was significantly different from the general position $(M=1.94, \mathrm{SD}=0.64)$. The mean score for the professional position $(M=2.46, \mathrm{SD}=0.53)$ was also significantly different from the general position $(M=1.94, \mathrm{SD}=0.64)$.

The relationship between the mean perception scores for the effectiveness of the PMS and PA fairness was investigated using the Pearson product-moment correlation coefficient. There was a small positive correlation between the two variables $(r=0.204, n=81, p<0.001)$ with lower levels for the perception scores on the effectiveness of the PMS associated with lower levels for the perception scores on PA fairness.

\section{Discussion Outline of results}

The results of the study point to serious shortcomings in the implementation of the PMS and the PA process. The purpose of the first research question was to measure employees' perceptions of the effectiveness of the PMS. The perceived effectiveness of the PMS was measured regarding two organisational factors, namely employee involvement and management commitment. The low mean perception score for the employee involvement subscale revealed that employees are not involved in the development of the PMS. The results from Tung et al. (2011, p. 1296) also show low employee participation levels in the PMS and reveal that top management support is associated with the effectiveness of the PMS. The employees perceived top management support and commitment to be moderately effective. However, the average mean score of the scale indicated that employees assessed their PMS to be ineffective.

The second research question sought to measure employees' perceptions of the fairness of their PAs. The mid-point mean score for appraiser's knowledge of PA indicated that employees' perceptions were neutral. The lower than midpoint mean scores for the employee participation, employee development, goal establishment and appraisal follow-up subscales and total scale indicated that there was a lack of participation in the PA process. Also, PAs were not done for development purposes, and performance follow-ups or feedback sessions were not conducted on a regular basis. Furthermore, employees were not involved in goal setting. The low overall mean score for the scale indicated that employees' perceived their PAs to be unfair.
The third research question aimed to investigate if there is a difference in the mean perception scores of the effectiveness of the PMS and PA fairness between men and women, and different age groups, departments and positions. The control variables gender, age group, department and position showed no significant difference in the mean perception scores for the effectiveness of the PMS. However, the mean perception scores for PA fairness for the Assets and Facilities Department were significantly lower than those of the Human Resources Department. This is indicative of some deficiencies in the appraisal process in the Assets and Facilities Department. Respondents occupying general positions returned significantly lower mean scores for PA fairness compared to those in managerial and professional positions, which indicates serious shortcomings in their appraisal process.

The fourth research question sought to establish if there is a correlation between the mean perception scores for the effectiveness of the PMS and PA fairness. There was a small positive correlation between the two variables, with low perception scores for the effectiveness of the PMS associated with low perception scores for PA fairness. The PMS includes PAs as a subset. Therefore, PMS cannot be effective if the appraisal process is perceived to be unfair.

\section{Practical implications}

This study has identified significant deficiencies in the implementation and practice of the PMS and PA fairness by line managers. The findings of this research show that managers should improve employee involvement to ensure the effectiveness of the PMS. The findings also revealed shortcomings regarding how managers conduct PAs such as a lack of participation in the PA process, PAs did not contribute to the development of employees, feedback was not given on a regular basis and employees were not involved in goal setting. These shortcomings should be addressed to ensure that employees perceive the PA process to be fair.

\section{Limitations and recommendations}

Regarding future research, it is recommended that employee perceptions from other public sector institutions be studied to obtain a more representative sample. Future research should also focus on additional organisational factors that may influence the effectiveness of the PMS, such as performance training, employee recognition, stakeholder involvement, internal resources and the link between performance and rewards. Future research should also include the influence of other factors, such as communication and interpersonal relations between line managers and employees, self-efficacy of line managers, charismatic leadership, procedural justice, distributive and interactional justice and trust in line managers especially concerning the perceived fairness of PA.

\section{Conclusion}

Line managers in public sector institutions need to understand their roles and responsibilities in the 
implementation and practice of PMSs and PAs. The findings showed that employees perceived the PMS to be ineffective. Employees should be involved with and engaged in the design of the PMS.

The lack of employee participation in the appraisal process, the fact that appraisals are not conducted with a developmental goal, the absence of clear performance standards and goals and the fact that the determination of organisational and individual objectives is not based on agreement between managers and employees all contribute to employees' perceptions that the PA process is unfair. The results indicate that employees seem to be informed of and knowledgeable on the performance management directive and view the PMS as a suitable tool to evaluate the performance of individuals. Therefore, the PMS policy and practical guidelines are perceived to be effective, but the implementation and practice by line managers are characterised by significant shortcomings.

The aims of the current study were to provide an empirical analysis of the association between two organisational factors (namely employee involvement and management commitment) and the effectiveness of the PMS and to investigate the factors that determine employees' perceptions of PA fairness. The results indicate that employees perceive their PMS to be ineffective and their PAs to be unfair.

This research study adds to the body of knowledge by quantifying the perceptions of employees regarding the two organisational factors that influence the effectiveness of the PMS and the six factors that influence PA fairness. The quantification of these perceptions will enable line managers to develop and implement remedial strategies to ensure the effectiveness of the PMS and fairness of the PA process.

\section{Acknowledgements Competing interests}

The authors declare that they have no financial or personal relationships which may have inappropriately influenced them in writing this article.

\section{Authors' contributions}

P.A.B. was the academic supervisor and responsible for the design of the project and wrote this article. M.M. was the principle investigator responsible for the fieldwork. S.S. was responsible for the literature review.

\section{References}

Aguinis, A. (2009). Performance management. (2nd edn.). Upper Saddle River, NJ: Pearson Prentice Hall.

Ahmad, R., \& Azman Ali, N. (2004). Performance appraisal decision in Malaysian public service. International Journal of Public Sector Management, 17(1), 48-64. http://dx.doi.org/10.1108/09513550410515565

Ahmed, I., Ramzan, M., Mohammad, S.K., \& Islam, T. (2011). Relationship between perceived fairness in performance appraisal and OCB: Mediating role of organizational commitment. International Journal of Academic Research, 3(5), organizatic
Appelbaum, S.H., Roy, M., \& Gilliland, T. (2011). Globalization of performance appraisals: Theory and applications, Management Decision, 49(4), 570-585. http://dx.doi.org/10.1108/00251741111126495

Armstrong, M. (2009). Armstrong's handbook of human resource management practice. (11th edn.). London: Kogan Page.

Babbie, E. (2004). The practice of social research. (10th edn.). Walworth, WI: Thomson Learning Inc.

Boachie-Mensah, F.O., \& Seidu, P.A. (2012). Employee's perception of performance appraisal system: A case study. International Journal of Business and Management 7(2), 73-78. http://dx.doi.org/10.5539/ijbm.v7n2p73

Brown, M., \& Benson, J. (2003). Rated to exhaustion? Reactions to performance appraisal processes. Industrial Relations Journal, 34(1), 67-81. http://dx.doi. org/10.1111/1468-2338.00259

Brown, M., Hyatt, D., \& Benson, J. (2010). Consequences of the performance appraisal experience. Personnel Review, 39(3), 375-396. http://dx.doi.org/10.1108/004834 81011030557

Culbertson, S.S., Henning, J.B., \& Payne, S.C. (2013). Performance appraisal satisfaction. Journal of Personnel Psychology, 12(4), 189-195. http://dx.doi. org/10.1027/1866-5888/a000096

Deb, T. (2008). Performance appraisal and management concepts, antecedents and implication. New Dehli: Excel Printers.

Dewettinck, K., \& van Dijk, H. (2013). Linking Belgian employee performance management system characteristics with performance management system effectiveness: Exploring the mediating role of fairness. The International Journal of Human Resource Management, 24(4), 806-825. http://dx.doi.org/10.1080/09 585192.2012.700169

Evans, E.M., \& McShane, S.L. (1988). Employee perceptions of performance appraisal fairness in two organizations. Canadian Journal of Behavioural Science, 20(2), 177. http://dx.doi.org/10.1037/h0079926

Farndale, E., \& Kelliher, C. (2013). Implementing performance appraisal: Exploring the employee experience. Human Resource Management, 52(6), 879-897. http:// dx.doi.org/10.1002/hrm.21575

Fryer, K., Antony, J., \& Ogden, S. (2009). Performance management in the public sector. International Journal of Public Sector Management, 22(6), 478-498. http://dx.doi.org/10.1108/09513550910982850

Goh, S.C. (2012). Making performance measurement systems more effective in public sector organizations. Measuring Business Excellence, 16(1), 31-42. http://dx.doi. org/10.1108/13683041211204653

Greenberg, J. (1986). Determinants of perceived fairness of performance evaluations. Journal of Applied Psychology, 71(2), 340. http://dx.doi.org/10.1037/0021 9010.71.2.340

Gruman, J.A., \& Saks, A.M. (2011). Performance management and employee engagement. Human Resource Management Review, 21(2), 123-136. http:// dx.doi.org/10.1016/j.hrmr.2010.09.004

Haines, V.Y., III, \& St-Onge, S. (2012). Performance management effectiveness: Practices or context? The International Journal of Human Resource Management, 23(6), 1158-1175. http://dx.doi.org/10.1080/09585192.2011.561230

Human Resources Directive (HRD.11). (2011). Integrated Performance Management System (IPMS).

Kavanagh, P., Benson, J., \& Brown, M. (2007). Understanding performance appraisa fairness. Asia Pacific Journal of Human Resources, 45(2), 132-150. http://dx.doi. org/10.1177/1038411107079108

Leedy, P.N., \& Ormrod, J.E. (2005). Practical research. (8th edn.). Upper Saddle River, New Jersey: Pearson Merrill Prentice Hall.

Locke, E.A., \& Latham, G.P. (2002). Building a practically useful theory of goal setting and task motivation: A 35-year odyssey. American Psychologist, 57(9), 705. http:// dx.doi.org/10.1037/0003-066X.57.9.705

Mansor, N.N.A., Chakraborty, A.R., Yin, T.K., \& Mahitapoglu, Z. (2012). Organizational factors influencing performance management system in higher educational institution of South East Asia. Procedia-Social and Behavioral Sciences, 40, 584-590. http://dx.doi.org/10.1016/j.sbspro.2012.03.234

Martin, S., \& Davis, H. (2001). What works and for whom? The competing rationalities of 'Best Value'. Policy \& Politics, 29(4), 465-475. http://dx.doi.org/10.1332/ 0305573012501477

McAdam, R., Hazlett, S.A., \& Casey, C. (2005). Performance management in the UK public sector: Addressing multiple stakeholder complexity. International Journal of Public Sector Management, 18(3), 256-273. http://dx.doi.org/10.1108/095135 50510591542

Messer, B.A., \& White, F.A. (2006). Employees' mood, perceptions of fairness, and organizational citizenship behavior. Journal of Business and Psychology, 21(1), 65-82. http://dx.doi.org/10.1007/s10869-005-9018-x

Narcisse, S., \& Harcourt, M. (2008). Employee fairness perceptions of performance appraisal: A Saint Lucian case study. The International Journal of Human Resource Management, 19(6), 1152-1169. http://dx.doi.org/10.1080/09585190802051451

Nel, P.S., Werner, A., Poisat, P., Sono, T., Du Plessis, A., \& Ngalo, O. (2011). Human resource management. (8th edn.). Cape Town: Oxford University Press.

Palaiologos, A., Papazekos, P., \& Panayotopoulou, L. (2011). Organizational justice and employee satisfaction in performance appraisal. Journal of European Industria Training, 35(8), 826-840. http://dx.doi.org/10.1108/03090591111168348

Pettijohn, C., Pettijohn, L.S., Taylor, A.J., \& Keillor, B.D. (2001). Are performance appraisals a bureaucratic exercise or can they be used to enhance sales-force
satisfaction and commitment? Psychology \& Marketing, 18(4), 337-364. http:// dx.doi.org/10.1002/mar.1011 
Poister, T.H. (2008). Measuring performance in public and nonprofit organizations. San Francisco, CA: John Wiley \& Sons.

Pulakos, E.D. (2004). Performance management: A roadmap for developing implementing and evaluating performance management systems. Alexandria, VA: SHRM Foundation.

Ramulumisi, T.V., Schultz, C.M., \& Jordaan, C.J. (2015). Perceived effectiveness of a performance management system. Journal of Contemporary Management, 12, 517-543.

Rowland, C.A., \& Hall, R.D. (2013). Perceived unfairness in appraisal: Engagement and sustainable organizational performance. EuroMed Journal of Business, 8(3) 195-208. http://dx.doi.org/10.1108/EMJB-06-2013-0034

Saeed, M.K., \& Shahbaz, N. (2011). Employees' perceptions about the effectiveness of performance appraisals: The case of Pakistan. SIU Journal of Management, 1(1), 58-59.

Sanger, M.M. (2008). From measurement to management: Breaking through the Barriers State and local performance. Public Administration Review, 68(1), 70-83. http://dx.doi.org/10.1111/j.1540-6210.2008.00980.x

Seijts, G.H., \& Latham, G.P. (2005). Learning versus performance goals: When should each be used? The Academy of Management Executive, 19(1), 124-131. http:// dx.doi.org/10.5465/ame.2005.15841964

Selden, S., \& Sowa, J.E. (2011). Performance management and appraisal in human service organizations: Management and staff perspectives. Public Personnel Management 40(3), 251-264. http://dx.doi.org/10.1177/009102601104000305

Sharma, N.P., Sharma, T., \& Agarwal, M.N. (2016). Measuring employee perception of performance management system effectiveness: Conceptualization and scale development. Employee Relations, 38(2), 224-247. http://dx.doi. org/10.1108/ER-01-2015-0006

Smither, J.W., \& London, M. (Eds.). (2009). Performance management: Putting research into action (Vol. 21). San Francisco, CA: John Wiley \& Sons.
Sole, F. (2009). A management model and factors driving performance in public organizations. Measuring Business Excellence, 13(4), 3-11. http://dx.doi.org/ $10.1108 / 13683040911006747$

Stredwick, J. (2005). An introduction to human resource management. (2nd edn.). London: Elsevier Ltd.

Swanepoel, B.J., Erasmus, B.J., \& Schenk, H.W. (2009). South African human resource management theory and practice. (4th edn.). Cape Town: Juta \& Co Ltd.

Tung, A., Baird, K., \& Schoch, H.P. (2011). Factors influencing the effectiveness of performance measurement systems. International Journal of Operations \& Production Management, 31(12), 1287-1310. http://dx.doi.org/10.1108/014 43571111187457

Tuytens, M., \& Devos, G. (2012). Importance of system and leadership in performance appraisal. Personnel Review, 41(6), 756-776. http://dx.doi.org/10.1108/004834 81211263692

Vasset, F., Marnburg, E., \& Furunes, T. (2010). Employees' perceptions of justice in performance appraisals: Frøydis Vasset and colleagues present a research study into the perceptions of justice in performance appraisals by nurses and auxiliary nurses in Norway's municipal health service. Nursing Management, 17(2), 30-34. http://dx.doi.org/10.7748/nm2010.05.17.2.30. c7727

Vasset, F, Marnburg, E, \& Furunes, T. (2011). The effects of performance appraisal in the Norwegian municipal health services: A case study. Human Resources Health, 9(1), 1-12. http://dx.doi.org/10.1186/1478-4491-9-22

Verbeeten, F.H. (2008). Performance management practices in public sector organizations: Impact on performance. Accounting, Auditing \& Accountability Journal, 21(3), 427-454. http://dx.doi.org/10.1108/09513570810863996 